\title{
Neue Musterverträge für Doppelpraxen
}

\author{
Rechtsdienst FMH
}

Wir haben den langjährigen Standardvertrag für Doppelpraxen überarbeitet und mit ausführlichen Erläuterungen versehen. Neu gibt es den Mustervertrag in zwei Varianten, eine für die Neugründung einer Doppelpraxis, eine für den Einstieg eines neuen Partners in eine bestehende Praxis. Darüber hinaus habe wir ein Textmodul für Doppelpraxen im sogenannten «Poolsystem», wie es v.a. bei Ärzte-Ehepaaren üblich ist, formuliert.

\section{Achtung: Mehrwertsteuer verlangt schriftlichen Gesellschaftsvertrag}

Nach unserer Erfahrung wird in Gruppenpraxen meistens ein schriftlicher Gesellschaftsvertrag abgeschlossen. Es kommt aber immer wieder vor, dass die Zusammenarbeit auf rein mündlichen Vereinbarungen beruht oder dass der Gesellschaftsvertrag irgendwann einmal im Entwurfstadium steckengeblieben ist und nie unterzeichnet wurde. Hier sollte dringend Remedur geschaffen werden: Die eidgenössische Steuerverwaltung macht die Mehrwertsteuerausnahme von Gruppenpraxen unter anderem von der formalistischen Bedingung abhängig, dass ein schriftlicher und unterzeichneter Gesellschaftsvertrag vorliegt. Dies gilt gemäss der (unverständlichen) Praxis der Steuerverwaltung ausdrücklich auch für Praxen von Ärzte-Ehepaaren.

\section{Weitere Musterverträge}

Die überarbeiteten Musterverträge für Doppelpraxen ergänzen die Palette von Standardverträgen, welche die FMH ihren Mitgliedern exklusiv und unentgeltlich zur Verfügung stellt:

- Zusatzvereinbarungen für die Miete einer Arztpraxis;

- Praxisübernahme;

- Gesellschaftsvertrag über die Mitbenützung der Praxisinfrastruktur;

- Mustervertrag Praxisstellvertretung / Lohnempfehlungen;

- Arbeitsvertrag Praxisassistenz (im Rahmen der Weiterbildung);

- Arbeitsvertrag für die Medizinische Praxisassistentin.

Am einfachsten bestellen Sie die Verträge via Internet auf www.fmh.ch $\rightarrow$ unsere Dienstleistungen $\rightarrow$ Recht $\rightarrow$ Musterverträge, oder telefonisch oder schriftlich beim Sekretariat Rechtsdienst, Elfenstrasse 18, 3000 Bern 16, Tel. 03135911 11, Fax 03135911 12, E-Mail: lex@hin.ch.

Bitte beachten Sie, dass der Rechtsdienst der FMH aus Kapazitätsgründen keine umfassenden individuellen Vertragsberatungen übernehmen kann. Am besten wenden Sie sich als erste Anlaufstelle an Ihren Treuhänder, der im Idealfall über ein Netz von spezialisierten Beratern aus den Bereichen Finanzierung, Versicherung und evtl. Vertragsrecht verfügt. Andernfalls kann Ihnen auch die standeseigene FMH Consulting Services (www.fmhservices.ch, Tel. 04192500 77) weiterhelfen. 